\title{
$\bigcirc$ VEHICLE TO GRID USING BROADBAND COMMUNICATIONS
}

\author{
Mike Dennis, Australian National University \\ Bethany Thompson, Australian National University
}

The impending mass electrification of road transport, driven by concerns for climate change and sustainability, enables an opportunity to substantially reduce greenhouse emissions from passenger vehicles and to simultaneously provide services to the electricity grid. Electricity grids are characterised by a lack of storage capacity, which can be provided by grid connected electric vehicles charging and discharging their batteries under centralised control. This paper argues that the Vehicle to Grid (V2G) methodology offers operational, financial and sustainability synergies between vehicles and electricity grids. Broadband communications is an essential service to facilitate the aggregation, distributed control and metering of V2G services.

\section{INTRODUCTION}

During the 20th century, industrialised countries built two massive energy conversion infrastructures: electricity grids and road transport fleets. Both of these can be considered to be key enabling mechanisms for economic growth. To date, there has been little interaction between electricity grids and road transport, and both are stained by appallingly low energy conversion efficiency to the end use service they ultimately provide. As a result, both manifest high environmental impact through gaseous and thermal emissions, the former totalling $70 \%$ of all greenhouse gas emissions in Australia.

The focus of the $21^{\text {st }}$ century will be on sustainability of our planet's life support systems with implications for energy provision, food supply and population health amongst other issues. The theme of sustainability may be embodied by the understanding that we should allow future generations to have equal access to the quality of life that our generation currently enjoys. However, the major shift in thinking that must happen is to change the association of sustainability with cost to an association with opportunity and benefit.

There are compelling sustainability reasons to encourage interactivity between electricity supply and road transport. Perhaps the most important is to lower the emissions from road transport, by moving away from hydrocarbon transport fuels to grid based renewable electricity. The motivation to lower emissions from grid electricity production is in turn supported by the presence of electric vehicles connected to the grid. Electric vehicles are complimentary to intermittent renewable energy generators as a source of constantly connected, high capacity and fast response electricity storage. The connectivity, capacity and latency attributes are also common to broadband communications networks.

Indeed, a key driver of future sustainability, and therefore prosperity, will be the ability to communicate information effectively. Broadband communications will be the "roads" of this century, the source of new business opportunities and productivity gains. The Australian government have committed to rolling out an open access, high performance broadband network to homes and businesses with comprehensive coverage. This will open up many opportunities to 
explore the link between connectivity and sustainability, both of which are essential for our future prosperity.

In a report to the Department of Broadband, Communications and the Digital Economy (BAG 2003), the Broadband Advisory Group suggests that broadband could produce economic benefits of $\$ 12$ billion to $\$ 30$ billion per annum to Australia, assuming that broadband is adopted universally over the next 25 years. Broadband uptake levels approached 50\% in Australian homes by 2007 (ABS 2007), which suggests that Australians are comfortable with the idea of broadband applications.

In this paper, a further real-time application of broadband is suggested with sustainability benefits for road transport fleets and synergistic benefits for electricity supply. The application is known as Vehicle to Grid (V2G) and involves mass electrification of the passenger vehicles.

Firstly, evolving technology options for electric vehicles are explored. This is followed by an examination of the characteristics of Australia's present electricity supply. We argue that broadband communications is absolutely necessary to facilitate future beneficial interaction between electric vehicles and the electricity grid. Original modelling support is provided throughout this paper to demonstrate that there are several incentives and no strong barriers to feasibility of V2G in Australia.

\section{ELECTRIFICATION OF ROAD TRANSPORT}

Road transport is responsible for one fifth of planet earth's greenhouse gas emissions and around 14\% of Australia's emissions (Australian Government Department of Climate Change 2006). Furthermore, it is growing rapidly due to the increasing number vehicles on the road, increasing mass of vehicles and increasing road congestion.

A transition from hydrocarbon fuels is desirable from many points of view including:

- Long term availability and cost of hydrocarbon fuels

- Security of supply

- Safety of handling of hydrocarbon fuels

- Low conversion efficiency and resulting high emissions from prime movers

The most promising options for reduced hydrocarbon dependency include hydrogen-based fuel cells and electric vehicles. Biofuels have been excluded from this study due to concerns over their perceived conflict over land use for food crops.

Hydrogen fuels promise zero local emissions but have a number of drawbacks. The generation, distribution and storage of hydrogen are problematic and these problems have persevered through extensive research. Fuel cells companies suffered major divestment around 2001 when investors finally lost confidence with the technology after many years of high expectation.

An electric vehicle offers the important advantages of being inherently multi-fuel and having an existing supply infrastructure. This allows the flexibility of providing a fuel source that can be generated from the source that is most appropriate to the region, and preferably a renewable resource. A further important advantage of electric vehicles is their ability to dynamically interact with their energy source in a bi-directional fashion. No other transport fuel is capable of this at reasonable efficiency and the implications for lowering transport emissions are profound. 
At this point it would be pertinent to note the specific emissions from road transport. The average petrol-powered passenger vehicle typically consumes $11 \mathrm{~L}$ of fuel (ABS 2006) and produces $25 \mathrm{kgCO}_{2}$-e for each $100 \mathrm{~km}$ travelled (Australian Government Department of Climate Change 2008). These high greenhouse gas emissions are a direct result of the poor conversion efficiency of internal combustion drivetrains, typically no better than $15 \%$ in a city cycle (Williamson et al 2006). An equivalent electric car has typical drivetrain conversion efficiency exceeding $85 \%$. If the electric car's energy were to be supplied from a contemporary Australian black coal thermal power station, one would expect emissions of less than $18 \mathrm{kgCO}_{2}$-e per $100 \mathrm{~km}$ travelled and these emissions would then be centralised where it is logistically easier to deal with them. Urban air quality would be improved with potential benefits for urban population health.

Thus one might conclude that an electric car sourcing power from a fossil fuel power station in Australia still has lower emissions than an equivalent petrol powered car. To this advantage may be added the important implications for Australia's balance of trade, safety, energy supply security and the sustainability benefit of being able to address the emissions problem by sourcing renewable electricity generation for transport demand.

Readers will be curious to understand the potential impact of mass electrification of Australia's road fleet on electricity generation demand. For a daily city cycle commute of $60 \mathrm{~km}$, an electric vehicle would be expected to consume $10 \mathrm{kWh}$ of electricity (Tomic and Kempton 2005). If all passenger cars, about two thirds of all road vehicles, were to convert to electric propulsion by 2030 , our calculations suggest an expected $12 \%$ increase in projected electricity generation required to cover the additional load based on business-as-usual forecast electricity demand growth (ESAA 2007).

Given that Australia's Mandatory Renewable Energy Target (MRET) demands that $20 \%$ of all electricity generation is to come from renewable sources by 2020 (Tambling 2003) it would appear that electricity supply is not a strong impediment to the notion of mass vehicle electrification in Australia.

The examination of bulk electricity supply was localised by region on Australia's eastern interconnected electricity grid (Figure 1). Due to the close correlation between vehicle ownership and electricity generation capacity by region (in turn related to population), no regional constraints in the V2G proposal are expected to cause concern.

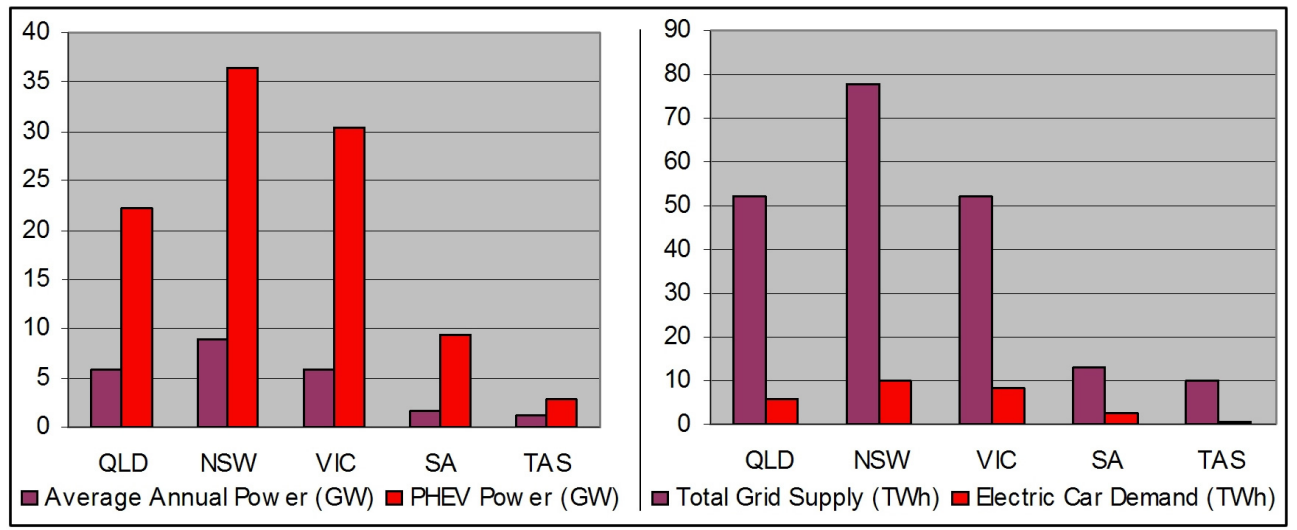

Figure 1 The ability of electric vehicles to provide power to the electricity grid and the annual energy demand on the grid by region. 
Further to the benefits already stated, a recent Australian study suggests that a subsidy of $\$ 5000$ per electric vehicle, declining to $\$ 1000$ per vehicle by 2015 , would benefit Australia's balance of trade by $\$ 22$ b by 2025, mainly justified on the cost of oil imports (Hunswick 2007). At a total cost of $\$ 7.3 \mathrm{~b}$, these subsidies represent a similar scale of investment to that of the government's proposals for broadband networks. Reducing Australia's dependency on oil is a valuable sustainability outcome.

So far, the ability of passenger vehicles to deliver sustainable transport has not been closely examined. The V2G concept relies on specific attributes of electric vehicles, their interaction with the electricity grid and the communications that enables that interaction.

\section{ELECTRIC VEHICLE TECHNOLOGIES}

Although electric vehicles predated petrol vehicles, the high energy density and low cost of hydrocarbon fuels has afforded great convenience in transport applications. Only recently has portable electricity storage technology matured to a level at which manufacturers are prepared to mass produce electric powered road vehicles.

The nature of use of electric vehicles is characterised by short intense discharging of the battery, long charging cycles and a long periods of inactivity. Opportunities to use a vehicle for purposes other than transport would be desirable in encouraging the uptake of electric vehicles. It has been shown that this is financially attractive to the vehicle owner and the electricity utility while having collateral sustainability benefits (see Table 1).

\begin{tabular}{|l|c|c|c|c|c|}
\hline & Petrol & Fuel cell & HEV & PHEV & EV \\
\hline Example & $\begin{array}{c}\text { Honda FCX } \\
\text { Clarity }\end{array}$ & Toyota Prius & GM Volt & Tesla Roadster \\
\hline Energy Storage & $450 \mathrm{kWh}$ & Unknown & $2 \mathrm{kWh}$ & $16 \mathrm{kWh}$ & $56 \mathrm{kWh}$ \\
\hline $\begin{array}{l}\text { Conversion } \\
\text { efficiency }\end{array}$ & $\begin{array}{c}\text { Poor } \\
<15 \%\end{array}$ & $\begin{array}{c}\text { Good } \\
60 \%\end{array}$ & $\begin{array}{c}\text { Moderate } \\
30 \%\end{array}$ & $\begin{array}{c}\text { Excellent } \\
>80 \%\end{array}$ & $\begin{array}{c}\text { Excellent } \\
>80 \%\end{array}$ \\
\hline $\begin{array}{l}\text { Energy cost per } \\
\mathbf{1 0 0 k m}\end{array}$ & $\$ 14$ & $\mathrm{~N} / \mathrm{A}$ & $\$ 5$ & $\mathrm{~N} / \mathrm{A}$ & $\$ 1.50$ \\
\hline $\begin{array}{l}\text { Bi-directional } \\
\text { energy transfer }\end{array}$ & No & $\begin{array}{c}\text { Yes, poor } \\
\text { efficiency }\end{array}$ & $\begin{array}{c}\text { Yes, limited } \\
\text { capacity }\end{array}$ & Yes & Yes \\
\hline
\end{tabular}

Table 1 Comparison of vehicle drivetrain technologies

Today's hybrid petrol/electric vehicles (HEV) are a transition technology towards fully electric vehicles. The primary energy source in these vehicles is hydrocarbon fuel and the several $\mathrm{kWh}$ of electrical storage is essentially an energy efficiency device. Nonetheless, the emissions of such vehicles is typically half that of an average Australian car on a city cycle, although the difference is much less pronounced in highway driving. Examples such as the Toyota Prius and Honda Insight have proved popular.

Some manufacturers now offer plug-in rechargeable hybrid electric vehicles (PHEV) and aftermarket kits are available to provide plug-in capability to HEVs. The PHEV uses electricity 
as an alternative primary energy source along with the convenience of recharging the vehicle's battery wherever electrical power is available. Such vehicles typically have $10-20 \mathrm{kWh}$ of battery capacity and are thus reliant on hydrocarbon fuel for backup motive power.

Only recently have electric only vehicles (EV) become a practical proposition, although they are still considered to be expensive. The Tesla Roadster EV has no less than $55 \mathrm{kWh}$ of battery capacity with outstanding sports car performance. This study shows that PHEV, rather than EV, technology is the most likely transition platform over the next 25 years that our models represent. Our modelling is based on PHEV technology with $20 \mathrm{kWh}$ battery capacity, a maximum $50 \%$ depth of discharge and $10 \mathrm{~kW}$ maximum discharge rate.

One might consider the nature of the electricity storage in the vehicle to be important. For the V2G application, the most important parameters are the storage efficiency, the amount of energy that can be exchanged and the rate at which energy can be exchanged. Fortunately, none of these factors present a problem with contemporary battery technology, although there are clear winners for other reasons.

Future generations of electric vehicles will most likely include ultra-capacitors in place of battery packs. Ultra-capacitors promise superior power and energy density in both space and weight to batteries, longer life and better recycling potential than contemporary batteries, thus reducing resource consumption. This is an important sustainability consideration if electric vehicles are to be deployed on a large scale. Furthermore, their low internal resistance leads to high storage efficiency and power densities suitable for regenerative braking energy recovery. The current benchmark for recovery of energy from a slowing vehicle sits at $57 \%$ with the Honda FCX Clarity and its Lithium battery. This energy efficiency benefit only applies to vehicles with electric energy storage.

The drivers that push battery technology for vehicle applications are well aligned with the needs of vehicle to grid connection. Examples of grid interface electronics for electric vehicles are already available and there appear to be no technical problems identified by real-world trials of this technology (Brooks 2002b).

The focus of the paper now turns to the state of Australia's electricity supply infrastructure with a view to its suitability for interaction with electric vehicles and the sustainability opportunities that might arise from such interaction.

\section{AUSTRALIA'S ELECTRICITY GRID}

The eastern seaboard of Australia, extending to Tasmania and South Australia, is serviced by one of the largest interconnected electricity grids in the world. This grid operates in the National Electricity Market (NEM) and is managed by the National Electricity Management and Marketing Company (NEMMCO). The role of NEMMCO is to operate the electricity grid and manage the spot market for wholesale electricity. It should be noted that this organisation operates under the National Electricity Rules (AEMC 2008) and has no imperative to provide electricity in a sustainable fashion.

The main market that NEMMCO operates is for the provision of bulk wholesale electricity to the transmission grid and this market operates by a tender process. This tender process is responsible for the increasing price of wholesale electricity during peak demand periods. NEMMCO also operate a number of other markets including a regulation market and a contingency market. 
The regulation service provides support for real-time matching of electricity supply and demand. Regulation is characterised by the need for moderate amounts of power that responds very quickly, but very little net energy exchange. Contingency support is required across the electricity grid to cover the shortfall in supply if the largest generator in that region were to fail.

Each of these services differs in control requirements, financial value, response time and frequency of need. We argue that electric vehicles are able to contribute substantially to peak load supply, regulation services and contingency support.

\section{PEAK ELECTRICITY SUPPLY}

Recently, the increasing popularity of domestic air conditioning has resulted in peak electricity demand growing even faster than baseload demand (NEMMCO 2007). Peak transmission losses are proportional to the square of the electrical current in the conductors, thus there is a rising sustainability penalty for additional peak loading. Furthermore, transmission assets must be sized on the peak current transmission and that capacity is used for a small proportion of the time as indicated by the load duration curve in Figure 2. The specific ratios for peak to average transmitted power to each NEM region are indicated in Table 2.

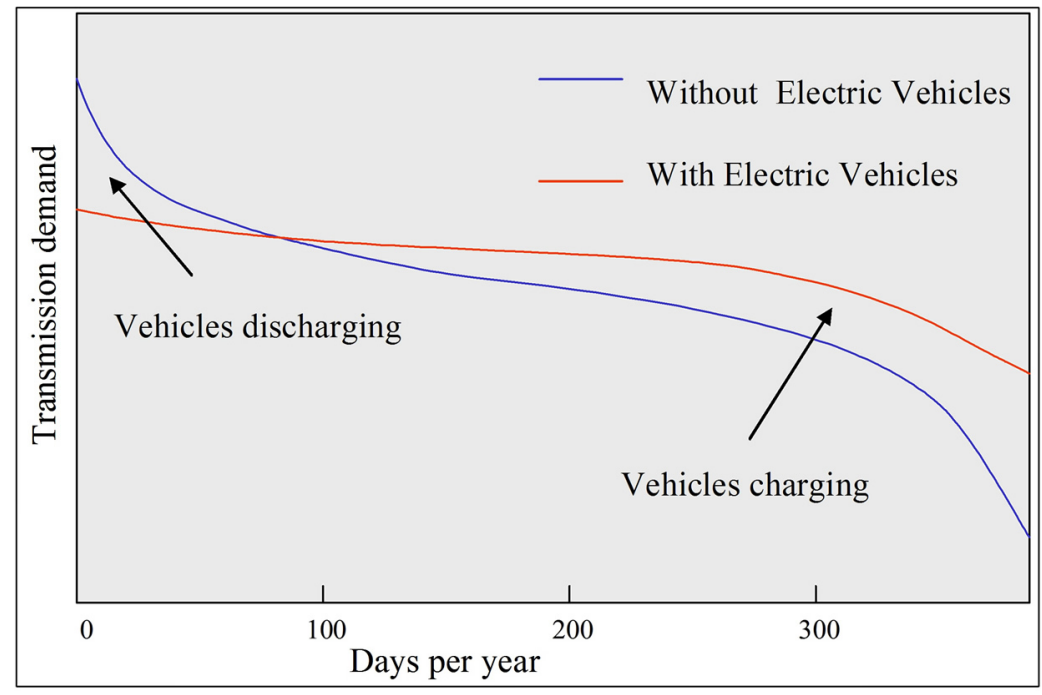

Figure 2 A typical load-duration curve for an electricity transmission line with and without electric vehicles

\begin{tabular}{|l|c|c|c|c|c|}
\hline & QLD & NSW & VIC & SA & TAS \\
\hline Baseload (MW) & 5846 & 8787 & 5798 & 1561 & 1158 \\
\hline Peakload (MW) & 8611 & 13871 & 9062 & 2916 & 1736 \\
\hline Peak: Base demand & $147 \%$ & $158 \%$ & $156 \%$ & $187 \%$ & $150 \%$ \\
\hline $\begin{array}{l}\text { Electric vehicles to } \\
\text { cover peak load }\end{array}$ & $13 \%$ & $14 \%$ & $11 \%$ & $15 \%$ & $25 \%$ \\
\hline
\end{tabular}

Table 2 Peak load demand and baseload demand in each NEMMCO region (source NEMMCO Annual Report 2007). 
The supply of peak electricity is typically met by generators with fast response and high unit production costs. Such generators are able to supply additional electricity to the grid, but this additional capacity must still be transmitted through the transmission lines, thus incurring transmission losses that equate to greenhouse gas emissions. Electric vehicles are a distributed form of peak generation and have the unique ability to flatten the load duration curve by supplementing local peak supply when necessary, thus reducing transmission requirements and in particular, peak transmission requirements. This approach is called load levelling by the electricity industry and is highly sought after.

The Electricity Supply Association of Australia estimates that $\$ 35 \mathrm{~b}$ will need to be spent in augmentation of Australia's electricity transmission assets by 2030, just to meet the forecast growth in demand for electricity. These grids must cope with peak demand capacity. An alternative, which partly offsets this expenditure, is to subsidise the entry of electric vehicles into the Australian passenger car market, as previously noted, with collateral benefits to the electricity grid.

The substitution of stored electricity in vehicle batteries for peak electricity only makes sense if the full cycle emissions from generating, transmitting, storing and retrieving the vehicle electricity are less than those associated with peak electricity generation and transmission at the time of use. This condition demands that the original energy source for V2G must be marginally more efficient than the most efficient peak generator on the grid, where efficiency is defined in terms of greenhouse gas emissions. Renewable energy sources are thus favoured for the charging of vehicle batteries.

There is anecdotal evidence to support the case for electric vehicles supplying peak power to the grid in Japan. A study performed by Kempton and Kubo (2000) conservatively suggested that the Kanto region could have $25 \mathrm{GW}$ or $25 \%$ of its peak demand supplied by electric vehicles by 2010 . The study suggests net present values to the grid in the order of \$US2500 per vehicle. A further study performed by Letendre and Kempton for the California Air Resource Board suggests that electric vehicles would also be capable of supplying peak power but cautioned that the economics were marginal for peak power in California (Kempton and Letendre 1997). However, they suggested that greater financial reward was available from ancillary grid services such as regulation.

\section{REGULATION SERVICES}

The real-time support for grid voltage and frequency by matching electricity demand with supply is known as regulation. There is an excellent match between the real-time grid demands and the ability of electric vehicles to provide high power and fast response to match this demand.

Regulation is a form of grid support by providing power rather than energy. Indeed, very little net exchange of energy takes place over a typical day of regulation. Electric vehicles are well suited to this service since their batteries are designed for high power delivery. The provision of regulatory service places little threat to the capacity of the vehicle to complete the next journey.

Importantly, electric vehicles are able to supply additional power (regulate up) or soak additional demand (regulate down). Currently, NEMMCO is able to regulate by modulating thermal power station output over a small range and pays a separate contract fee for this service, in the order of $\$ 0.35 / \mathrm{MWh}$. This represents an opportunity for electric vehicle owners to increase the utilisation of their vehicle asset. 
The Californian study (Kempton and Letendre 1997) indicated that regulation is a key driver for the inclusion of electric vehicles on the electricity grid. The reports indicate that the electricity grid benefits from a low cost source of regulation while vehicle owners are able to offset the cost of their bulk electricity by providing services to the grid operator.

It is very difficult to obtain meaningful data from NEMMCO regarding regulation contract settlement. Given that electric vehicle battery power capacity would far exceed the entire grid generating power, one may confidently assume that electric vehicles would easily meet the regulation requirements published by NEMMCO.

Thus it would be reasonable to conclude that electric vehicles would be up to the task of providing regulation services to the grid.

\section{CONTINGENCY SUPPORT}

NEMMCO are required by the electricity regulations to meet no less than $99.998 \%$ of electricity demand. This is a challenging target. NEMMCO keep watch on a key indicator known as Low Reserve Condition (LRC). The LRC indicates when a region is likely to have high probability of failure to meet demand due to a shortfall in contingency support in that region. The LRC dates are shown also in Table 3.

NEMMCO maintain around $850 \mathrm{MW}$ of contingency on the electricity grid, also known as spinning reserve. This spinning reserve is required to cover the loss of the biggest generating unit in each region of the National Electricity Market and is a need for backup power more than a need for backup energy. Such capacity must respond within 5 minutes and thus gas power plants are not usually considered for contingency support since they typically take 30 minutes to reach full power from cold start.

Indeed much of this spinning reserve is provided by the Snowy Mountains Hydro scheme, but interconnector constraints demand that local contingency is provided in some states as indicated in Table 3 (NEMMCO 2007). This additional capacity is essentially idle and represents poor use of capital. The table also shows that modest numbers of electric vehicles are sufficient to meet the regional contingency requirements. Although it was difficult to obtain data from NEMMCO on the value of contingency services, other studies (Kempton et al 2001, Letendre et al 2006) have concluded that the value of contingency support to vehicle owners could be as much as \$US1200 per annum.

\begin{tabular}{|l|c|c|c|c|c|}
\hline & QLD & NSW & VIC & SA & TAS \\
\hline $\begin{array}{l}\text { Load Shedding capacity } \\
\text { (MW) }\end{array}$ & 25 & 13 & 94 & 94 & 0 \\
\hline Reserve capacity (MW) & 560 & -1430 & 615 & -50 & 144 \\
\hline Low reserve constraint & $2007 / 08$ & $2013 / 14$ & $2010 / 11$ & $2010 / 11$ & $2016 / 17$ \\
\hline $\begin{array}{l}\text { Number of electric cars } \\
\text { to provide contingency }\end{array}$ & 56,000 & 143,000 & 61,500 & 5,000 & 14,400 \\
\hline
\end{tabular}

Table 3 NEM reserve capacity by state. Note that a negative reserve capacity indicates reliance on a transmission interconnect 


\section{UTILISING BROADBAND FOR VEHICLE TO GRID COMMUNICATIONS}

The vehicle to grid (V2G) concept operates when a vehicle is parked, plugged in to the electricity grid and accesses a broadband connection. The vehicle must be capable of supplying electricity to the grid and sinking electricity from the grid. Vehicle batteries provide a unique combination of storage capacity, fast response and high power density that make them an attractive resource for electricity grid support.

There are five main requirements for V2G:

1. the vehicle has access to the grid where it is parked,

2. there is control infrastructure and metering to manage the vehicle/grid connection,

3. there is high quality communications available between the vehicle and grid operator,

4. the grid must be able to exchange electricity bi-directionally with the vehicles,

5. the electricity should come from a low emissions source.

Most of the required infrastructure already exists and is technically uncomplicated. Usually, electric vehicles are driven by AC motors drawing from a DC battery pack, thus most of the power electronics to interact with an electricity grid already exists in an electric vehicle. Battery state of charge determination, power electronics, vehicle identification and interface controls are part of any modern electric vehicle's computer based management systems. The bottleneck for energy exchange would appear to be the electrical link between the grid and the vehicle, possibly requiring additional transformers and substations on the distribution network.

Thus it is not a paradigm shift in design for an electric vehicle to become grid interactive. However, the advantages that the V2G concept offers are substantial.

\section{LEVERAGED SUSTAINABILITY IMPLICATIONS}

It has already been noted that there are substantial greenhouse gas savings to be realised by converting the vehicle fleet to electric power. There are even greater synergies when one considers the services that electric vehicles can offer the grid electricity infrastructure in return.

Renewable energy sources are usually characterised by intermittent electricity generation. Individual solar installations typically have a capacity factor below $20 \%$, wind generators about $25 \%$ (Saddler et al 2007). On a larger scale, some have argued that the effects of intermittent generation from renewable sources are of lesser concern (Diesendorf 2006). Therefore, given the current capacity accounted for by renewable sources, we consider them less suitable for ancillary grid support services and dispatchable power in their current form (Hawkins 2008). A vehicle battery could act as storage for the intermittent renewable generator provided the correct aggregation arrangements can be reached.

Furthermore, the vehicle allows renewable generators to indirectly contribute to grid ancillary services, thus reducing the potential sustainability impact (and standby costs) of ancillary services. This can only work if these renewable generators are able to store their electricity - the missing factor to date. The financial structure is indeed very attractive to NEMMCO since contingency is essentially a pay-as-you-go service to the grid.

Any attempt to reduce the peak loading on transmission lines and costs associated with ancillary service provision will highlight the cost of the electricity generation source. This, in addition 
to carbon pricing, will assist in making renewable energy generators comparatively financially attractive.

The conclusion here is that the V2G model can substantially assist the penetration of renewable energy generators into the grid, that this approach is technically straight forward and shouldn't present onerous costs.

\section{BROADBAND FOR AGGREGATION}

The maintenance of grid electricity supply to customers represents a volatile real-time control problem in supply and demand balancing. The addition of decentralised capacity to the grid serves to complicate the control problem.

Aggregation of vehicle battery capacity is desirable to act as a buffer in electricity exchange and to simplify the logistics of control. NEMMCO would presumably prefer to communicate to a small number of service providers who in turn aggregate electric vehicle capacity, thus delegating the role of customer interfacing, metering and billing to these aggregators. NEMMCO regulations state that market participants must control at least $30 \mathrm{MW}$ of dispatchable generation capacity to be able to bid to the national electricity market. For V2G, that represents a nominal aggregation of 3000 vehicles. It would be in the aggregator's interests to maintain some kind of predictive capacity model and to attract a critical mass of vehicles in order to improve the dispatchability of the stored electricity.

The aggregator would operate in a competitive environment and may decide to offer incentives to customers, operating just like an Internet service provider. These incentives might include a retainer to customers and minimum rates for energy exchange or free parking in exchange for the use of the vehicle's battery.

Utilities are ideally placed to carry out the aggregation role, as they have an established customer base supported by billing infrastructure and experience with electricity distribution. Utilities also have the motivation to sell greater volumes of electricity and to tightly control their exposure to peak wholesale electricity prices.

The ability of V2G to achieve load levelling is enhanced by a high household electric vehicle ownership since household air conditioners are considered to be largely responsible for peak electricity grid loading (Johnston 2004). A survey conducted by the Australian Bureau of Statistics on vehicle ownership suggests that about $50 \%$ of Australian households own more than one car (ABS 2008).

\section{BROADBAND FOR METERING AND CONTROL}

The aggregator would be responsible for bidding, metering and billing for both bulk electricity exchange and ancillary services supplied to NEMMCO. Secure and accurate metering would be required at the charging point, which might transmit location, available capacity and billing data to the aggregator. This information would be passed to the aggregator in real-time over a broadband link so that the aggregator could confidently bid into the NEMMCO markets. This system would operate in real-time, requiring a high degree of automation. The communications link must be constantly available with short latency and potential to handle spikes in traffic volumes. Broadband would be the communications methodology of choice.

Electric vehicle owners would naturally be concerned that their vehicle is being used by the aggregator without their direct control. Presumably, the vehicle owner would wish to apply a 
set of operational constraints to the aggregator and these constraints would be likely to change over time (for example, the need to protect sufficient energy for the next journey). These constraints could be applied through a vehicle-mounted interface or over an Internet portal. In either case, strong real-time communications of this information to the aggregator is absolutely necessary if the aggregator is to generate dispatchable bids for electricity grid services.

Working with this information in real-time, the aggregator would generate market bids for the supply of peak electricity, grid regulation and contingency supply. NEMMCO would respond in real-time with dispatch commands to a small number of market participants. In the case of aggregators, these commands must in turn be communicated to large number of geographically disparate vehicles in real-time.

The communications from a dummy aggregator to a real electric vehicle has been demonstrated successfully in trial in California using wireless communications, and although not explicitly stated, it is reasonable to conclude from the text that the connection would have been broadband (Brooks 2002a).

There is great opportunity, particularly if a utility was involved as the aggregator, to locally generate and distribute the grid services. This distributed generation approach reduces the need for expensive augmentation of electricity transmission assets (Lovins et al 2002). Electric vehicles are inherently a distributed energy infrastructure and distributed infrastructure of any kind relies on the strength of its supporting communications.

\section{CONCLUSION}

Future sustainability of the road transport sector requires a progression away from hydrocarbon based fuels. Electric vehicles and plug-in hybrid vehicles would seem to be the technology of choice provided that the electricity could be sourced from a renewable supply.

If all passenger vehicles in Australia were to become electric vehicles, the impact on the electricity grid demand would be manageable and less than the 20\% Mandatory Renewable Energy Target set by the federal government for 2020 .

The presence of electric vehicles on the electricity grid provides a potential mass electricity storage facility, which can assist intermittent renewable energy generators to produce dispatchable power, therefore promoting their acceptance as a serious participant in the electricity market.

In addition, the collective battery capacity of electric vehicles is able to provide services to the electricity grid. Electric vehicles are able to contribute to reduction in peak electricity transmission requirements, supply regulation and grid contingency in substantial capacities. Electric vehicle owners would be rewarded for the provision of these services and would see an opportunity to increase the utilisation and payback on their asset while contributing towards cleaner urban air.

Pivotal to its success is logical aggregation of battery capacity. The most likely aggregators would be the electricity utilities and the concept absolutely requires the use of broadband communication services. Only with the implementation of broadband links between grid operators, utilities and vehicles can real-time management of V2G be realised. 


\section{ACKNOWLEDGEMENTS}

The authors wish to acknowledge the Telecommunication Society of Australia and $\mathrm{Mr}$ Robin Eckermann for establishing the Eckermann-TJA Prize for the Broadband Environmental Sustainability Challenge.

We would also like to thank the sponsors, Alcatel-Lucent.

\section{REFERENCES}

Australian Bureau of Statistics. 2008. ABS 1301.0, Australian Year Book.

Australian Bureau of Statistics. 2007. ABS 8146.0, Household Use of Information Technology.

Australian Bureau of Statistics. 2006. ABS 1370.0, Measures of Australia's Progress.

Australia Energy Market Commission (AEMC). The National Electricity Rules, last accessed 01/10/2008, available from www.aemc.gov.au/rules.php.

Australian Government Department of Climate Change. 2008. National Greenhouse Gas Accounting Factors, last accessed 01/10/2008 at http://www.climatechange.gov.au/inventory/2006/pubs/inventory2006.pdf.

Australian Government Department of Climate Change. 2006. National Greenhouse Gas Inventory, last accessed 01/10/2008 at http://www.climatechange.gov.au/workbook/index.html.

The Broadband Advisory Group (BAG). 2003. Australia's Broadband Connectivity, The Broadband Advisory Group's Report to Government, Australian Department of Broadband, Communications and the Digital Economy, last accessed 01/10/2008, available from: http://www.dbcde.gov.au/.

Brooks A. 2002a. Electric Drive Vehicles, A Huge New Distributed Energy Resource, AC Propulsion Inc, San Dimas, California.

Brooks A. 2002b. Vehicle to Grid Demonstration Project: Grid Regulation Ancillary Service with a Battery Electric Vehicle, prepared for the California Air Resources Board, California Environmental Protection Agency, AC Propulsion Inc.

Diesendorf, M. 2006. Wind Power in Australia, International Journal of Environmental Studies, 63 (6): $765-776$.

The Energy Supply Association of Australia (ESAA). 2007. Submission to the Task Group on Emissions Trading, Department of the Prime Minister and Cabinet.

Hunswick R. 2007. PHEVs, An energy policy silver bullet? [Presentation], Hunswick Consulting Pty Ltd.

Hawkins D. 2008. California ISO: Vehicle to Grid - A Control Area Operators Perspective, September, accessed at www.acpropulsion.com.

Johnston N. 2004. The Impact of Residential Air Conditioning on the Western Australian Electricity System, Western Australian Office of Energy.

Kempton, W; Kubo, T. 2000. Electric-drive Vehicles for Peak Power in Japan, Energy Policy, 28: 9-18.

Kempton, W; Letendre, S. 1997. Electric Vehicles as a New Power Source for Electric Utilities, Transportation Research. Part D, Transport and Environment, 2 (3): 157-175.

Kempton W.; Tomic J.; Letendre S.; Brooks A.; Lipman T. 2001. Vehicle to Grid Power: Battery, Hybrid and Fuel-Cell Vehicles as resources for distributed Electric Power in California, prepared for the California Air Resources Board, California Environmental Protection Agency and the Los Angeles Department of Water and Power Electric Transportation Program.

Letendre, S; Denholm, P; Lilienthal, P. 2006. Electric and Hybrid Cars: New Load or New Resource? Public Utilities Fortnightly, Dec: $28-37$.

Lovins A.; Datt E.; Feiler T.; Rabago K.; Swisher J.; Lehmann A.; Wicker K. 2002. Small is Profitable: The Hidden Economic Benefits of Making Electrical Resources the Right Size, Rocky Mountains Institute.

The National Electricity Market Management Company (NEMMCO) 2007. Australia's National Electricity Market, Statement of Opportunities, last accessed 29/09/2008 at www.nemmco.com.au. 
Saddler H.; Diesendorf M.; Denniss R. 2007. A Clean Energy Future for Australia, Clean Energy Future Group, Sydney and Melbourne.

Tambling G. 2003. Renewable Opportunities, A Review of the Operation of the Renewable Energy (Electricity) Act, Department of the Environment and Heritage, September.

Tomic J.; Kempton W. 2005. Vehicle to Grid Power Fundamentals: Calculating Capacity and Net Revenue, Journal of Power Sources.

Williamson, S; Srdjan, M; Emadi, S. 2006. Comprehensive Drive Train Efficiency Analysis of Hybrid Electric and Fuel Cell Vehicles Based on Motor-Controller Efficiency Modelling, IEEE Transactions on Power Electronics, 21 (3): 730-740.

Cite this article as: Dennis, Mike; Thompson, Bethany. 2009. 'Vehicle to grid using broadband communications'. Telecommunications Journal of Australia. 59 (1): pp. 3.1 to 3.13. DOI: 10.2104/tja09003. 